\title{
Consistência do planejamento e da gestão urbana na área metropolitana de Brasília
}

\author{
Consistency of planning and urban management in the metropolitan area of \\ Brasilia
}

Benny Schvarsberg[a] (1)

[a] Universidade de Brasília (UnB), Faculdade de Arquitetura e Urbanismo, Brasília, DF, Brasil

Como citar: Schvarsberg, B. (2019). Consistência do planejamento e da gestão urbana na área metropolitana de Brasília. urbe. Revista Brasileira de Gestão Urbana, 11, e20180088. https://doi.org/10.1590/2175-3369.011.e20180088

\section{Resumo}

De fato, é problemática a efetividade dos instrumentos de planejamento urbano em sua capacidade de controle do uso do solo e da incidência na dinâmica urbana. Utilizaram-se como fontes de pesquisa: planos diretores, zoneamentos e alvarás de construção anuais. 0 território da pesquisa foi a Área Metropolitana de Brasília (AMB), no Distrito Federal (DF) e também doze municípios goianos contíguos, levantando-se dados nas cidades: Taguatinga/DF, Samambaia/DF, Águas Lindas/GO e Planaltina/GO. Aplicaram-se os procedimentos metodológicos: i) coleta dos alvarás de 2013 a 2016; ii) organização dos dados em planilhas e mapeamento anual das construções no período; iii) análise do crescimento urbano, ou seja, sua consistência com o Plano Diretor e zoneamento. Concluiu-se pela limitação dos instrumentos de planejamento em orientar o crescimento urbano, bem como a reafirmação dos alvarás como indicadores empíricos confiáveis para a análise da dinâmica urbana, e a necessidade do planejamento e gestão territorial urbana integrada.

Palavras-chave: Planejamento urbano. Uso e ocupação do solo. Alvarás de construção.

\begin{abstract}
Instruments of urban planning and management in the control of land use and incidence in urban dynamics are problematized. Master Plans, Zoning, and Construction Permits are used as research sources. The Metropolitan Area of Brasília (AMB) - Federal District (DF) and twelve contiguous Goiás municipalities - is the research territory. Data are collected in the cities: Taguatinga/DF, Samambaia/DF and Planaltina/GO, applying methodological procedures: i) collecting the construction permits from 2013 - 2016; ii) organization of data in spreadsheets and annual mapping of buildings by use and size in the period; iii) analysis of urban growth: its consistency with the Master Plan and Zoning. It concludes with the limitation of planning instruments in guiding urban growth, by reaffirming construction permits as reliable empirical indicators for urban dynamics analysis, and the need for integrated territorial planning and management.
\end{abstract}

Keywords: Urban planning. Use, and occupation of the soil. Construction permits.

BS é arquiteto e urbanista pela Universidade Federal Fluminense, 1982. Mestrado em Planejamento Urbano e Regional pelo Instituto de PósGraduação e Pesquisa em Planejamento Urbano (IPPUR) e Regional da Universidade Federal do Rio de Janeiro. Doutorado em Sociologia pela Universidade de Brasília. e-mail: benny@unb.br 


\section{Introdução}

O objetivo desta pesquisa é contribuir tanto metodologicamente quanto conceitualmente com a análise crítica das relações entre planejamento e gestão urbana, especialmente o controle do uso do solo e da dinâmica real do crescimento urbano metropolitano. Para tanto, busca-se avaliar a eficácia dos instrumentos legais normativos em orientar e modelar os modos de ampliação e reprodução do tecido urbano utilizando-se para esse cotejo duas fontes básicas: i) as diretrizes e o zoneamento com seus parâmetros urbanísticos estabelecidos no Plano Diretor; e ii) os alvarás de construção emitidos em uma série histórica na vigência do Plano Diretor. Sua relevância insere-se nos esforços contemporâneos de aplicação do novo marco jurídico urbanístico brasileiro, estabelecido no capítulo de política urbana da Constituição Federal de 1988 e nos instrumentos regulamentados no Estatuto da Cidade (Lei Federal 10.257/01), em face dos processos reais de uso e ocupação do solo.

A problemática dos modos de crescimento urbano - que têm sido praticados no meio urbano edificado, de maneira formal ou informal, perante o aparato normativo urbanístico e edilício elaborado nos últimos anos - aponta limites e possibilidades que atualizam o conhecimento sobre o planejamento urbano, os desafios e a capacidade de incidência efetiva na ocupação, e também o uso do território. Para tal, a análise foca na Área Metropolitana de Brasília (AMB), delimitada pelo território do Distrito Federal (DF) e de doze municípios goianos pertencentes a RIDE-DF ${ }^{1}$ que lhe são fisicamente adjacentes. Quanto ao recorte temporal, a análise delimita-se no período de 2012 a 2015.

Os procedimentos metodológicos foram elaborados e aplicados no âmbito do projeto de pesquisa "Bases urbanísticas e institucionais para o planejamento e gestão territorial da Área Metropolitana de Brasília (AMB)" a partir de 2012². Tais bases são constituídas pelo conjunto de normas e dispositivos legais, instrumentos e recursos técnico-administrativos, avaliando-se sua capacidade de incidir sobre a ocupação deste território metropolitano. Considerando a amplitude desse conjunto, tomou-se o Plano Diretor vigente em cidades selecionadas da AMB, com o intuito de avaliar suas diretrizes de ordenamento territorial e de zoneamento, com base nos parâmetros urbanísticos que definem os padrões volumétricos e os destinos de atividades como referência para essas bases urbanísticas institucionais.

Para configurar uma amostra representativa deste extenso recorte espacial, estabeleceram-se três porções territoriais para a análise das dinâmicas urbana e imobiliária do território da AMB, e também de cidades de grande adensamento nessa área, tais como: a porção norte, em que foi selecionada a cidade de Planaltina de Goiás; a porção oeste, com escolha da cidade Águas Lindas de Goiás; e a porção central, com as cidades de Samambaia e Taguatinga do Distrito Federal. Ou seja, duas cidades do Distrito Federal e duas cidades goianas da periferia metropolitana.

A opção pelos alvarás de construção aprovados no período, como principal fonte de dados da pesquisa, justifica-se por ser tratar do instrumento básico da administração municipal, que autoriza a intervenção física, arquitetônica e urbanística de construção ou ampliação, sob a guarda da prefeitura no caso das cidades goianas, e da Administração Regional no caso do DF. A análise dos alvarás que foram emitidos e a sistematização dos usos e ocupações do solo em um período permitiu a observação de vetores predominantes do crescimento edilício urbano formal, ou seja, aquele crescimento edilício legalmente aprovado pelo poder público. Também não se deve desconsiderar os usos e ocupações dos solos informais, sem aprovação legal ou contrária às normas; contudo, pela inviabilidade de seu registro nos municípios investigados não foi possível considerá-los como variável de análise do crescimento urbano edilício.

Assim, os dados referentes aos alvarás que foram mapeados e cotejados de acordo com os Planos Diretores, principal instrumento de legislação urbanística local, e com os procedimentos metodológicos estão aqui indicados: i) levantamento dos alvarás de construção expedidos no período em amostra de cidades da AMB; ii) sistematização dos dados em planilhas e mapas registrando anualmente as novas

\footnotetext{
1 Região Integrada de Desenvolvimento Integrado do Distrito Federal e Entorno criada pela Lei Complementar no 94 de 1998 , regulamentada pelo Decreto no 2.710, de 04 de agosto de 1998, alterado pelo Decreto no 3.445, de 04 de maio de 2000, para efeito de articulação da ação administrativa da União, dos Estados de Goiás, Minas Gerais e o Distrito Federal.

${ }^{2} \mathrm{O}$ referido projeto de pesquisa foi desenvolvido neste período com apoio do CNPq.
} 
construções por uso do solo e porte por cidade; e iii) análises do crescimento urbano reveladas pela espacialização das novas construções, seus usos e portes, e sua consistência com o plano diretor e seus parâmetros urbanísticos.

Problematizando a maior autonomia ou dependência das cidades com relação ao centro metropolitano estabeleceram-se as hipóteses de pesquisa: i) os padrões de planejamento e planos diretores têm baixa incidência nas formas do crescimento urbano na dinâmica metropolitana da AMB; ii) na dinâmica metropolitana da AMB o predomínio de alvarás de atividades econômicas e institucionais (comércio e serviços, mistos, industriais e instituições) e residências multifamiliares verticais ${ }^{3}$ tende a expressar maior dinâmica e autonomia urbana; iii) no oposto, o predomínio de alvarás de residências unifamiliares e multifamiliares horizontais tende a expressar baixo dinamismo e autonomia urbana; reforçando o caráter de cidades dormitórios dependentes da cidade-mãe. Vide Figura 1.

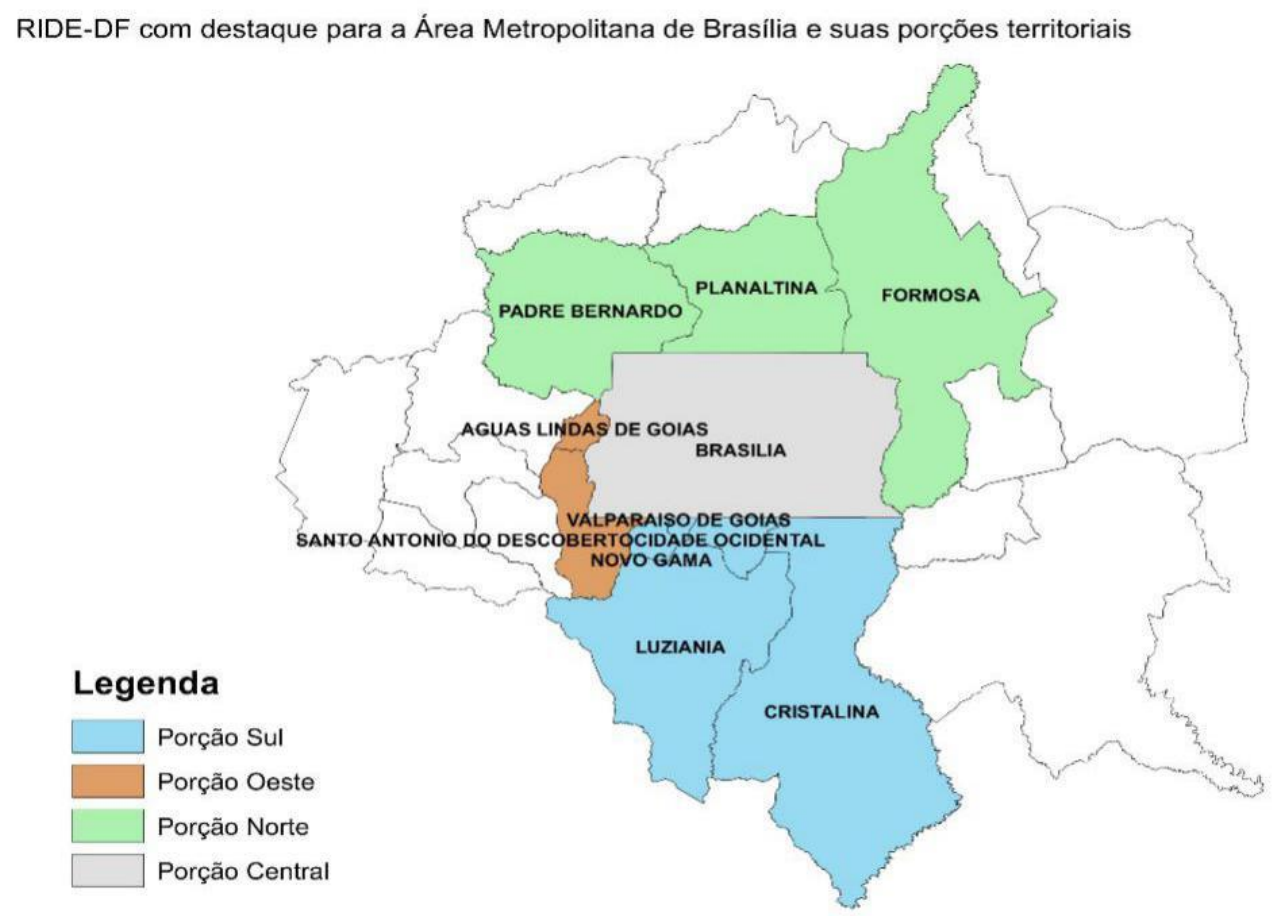

Figura 1 - Mapa RIDE-DF e Porções Norte, Oeste e Central da Área Metropolitana de Brasília. Fonte: CODEPLAN/ Distrito Federal, 2018.

\section{Aspectos teóricos acerca das regiōes metropolitanas brasileiras e da Brasília Metropolitana}

No lugar da forma compacta de cidade, que representou o processo histórico dominante em formação há anos, predomina desde meados do século 20 e com maior crescimento no início desse século, a tendência de uma população metropolitana distribuída e (des) organizada em áreas regionais em permanente expansão que possuem formas "desformes", ou aparentemente desordenadas. Pode-se falar de lógicas reproduzidas de loteamento, urbanisticamente simplificadas, mais próximas à noção de "acampamento" do que de cidade, que expandem e segmentam o tecido metropolitano em franjas periféricas e periurbanas. Aliado a esses problemas, há também o déficit de urbanidade comum tanto àquelas franjas quanto às áreas centrais e subcentros. Portanto, o aspecto fundamental do atual crescimento socioespacial, apontado por Gottdiener (1993), é de que "a vida urbana tornou-se portátil e

\footnotetext{
${ }^{3}$ Utiliza-se a expressão residencial multifamiliar vertical à edificação vertical de apartamentos, distinguindo-se da expressão residencial multifamiliar horizontal que se refere a condomínio fechado de casas.
} 
o mesmo ocorreu com a cidade". 0 autor também sugeriu o termo "região metropolitana polinucleada" para se referir ao processo de produção de assentamentos urbanos, distinguindo-o e criticando o discurso simplista "naturalizador" de que se trata de uma versão mais ampla da cidade contemporânea. Assim, novas formas de polinucleação metropolitana são desenvolvidas em locais onde prevalece mais a lógica de expansão do que desconcentração. Nesse processo, há o deslocamento de uma população crescente e do adensamento de atividades sociais, econômicas e políticas, em áreas distantes das tradicionais regiões citadinas e centros populacionais; não obstante, observa-se o predomínio da força polarizadora do centro.

Nessa perspectiva, o conceito de "expansão" descreveria padrões atuais de um crescimento urbano polinucleado, buscando apreender a dispersão regional de pessoas, comércios, atividades industriais e administração pública. Esse mesmo processo ocorre junto com a reestruturação destas regiões em domínios multicentrados dispersos por vários quilômetros, porém a distâncias crescentes. A expansão urbana e metropolitana polinucleada seria uma área produtora e resultante da correlação de forças dos agentes públicos e privados, da formação socioeconômica e da política dominante, em sua expressão territorial.

Em Brasília, o modelo territorial implantado de expansão polinucleada teve como efeito básico, proporcionar a centrifugação dos assalariados resguardando áreas centrais mais valorizadas e repletas de infraestrutura, bens, serviços e equipamentos, ou seja, para os agentes imobiliários e grandes construtoras - o Plano Piloto de Brasília (PPB).

Recuperando o conceito Metropolitano de Brasília na análise do Distrito Federal e Entorno, Ferreira (1985) apontava: “Decorridos 25 anos da implantação, a cidade já tem delineada sua área metropolitana à semelhança das demais metrópoles brasileiras; Brasília hoje não pode ser considerada só o Plano Piloto, como nos anos 50. Tampouco pode ser apenas a cidade com seus núcleos periféricos dispersos dos anos 60; essa cidade é agora a metrópole, que envolve além desses espaços os municípios vizinhos do Entorno." Após 21 anos Ferreira \& Steimberguer (2006) reafirmavam a noção metropolitana de Brasília, ampliando-a: "pode-se dizer que a Brasília real de 2006 configura território que abrange o DF e nove municípios goianos próximos - Água Fria de Goiás, Águas Lindas, Cidade Ocidental, Luziânia, Novo Gama, Padre Bernardo, Planaltina de Goiás, Valparaíso de Goiás e Santo Antônio do Descoberto - em que o DF é o Núcleo, constituído pela Sede e 16 cidades-satélites, uma das maiores concentrações urbanas do país, com 2,65 milhões de habitantes em 2000 e 75\% dessa população no DF."

Na experiência brasileira de Regiões Metropolitanas (RMs), destacaram-se dois momentos, ou seja, o primeiro nos anos 70, quando houve a integração do escopo da Política Nacional de Desenvolvimento Urbano no âmbito do II Plano Nacional de Desenvolvimento do regime militar de 1964. O fundamento dessa política tinha como base a lógica da expansão industrial onde se consolidavam as metrópoles como locus e expressão espacial desse contexto. Com base nas Leis Federais, foram criadas nove Regiões Metropolitanas que envolviam os principais centros urbanos nacionais e suas áreas de influência imediata, isto é, os municípios, definidos como mesma unidade socioeconômica. A justificativa era a implementação integrada de serviços comuns de interesse metropolitano. Constituir-se-iam as RMs como unidades de gestão e planejamento organizadas em estrutura de dois conselhos: deliberativo e consultivo.

A Constituição Federal de 1988 inaugurou o segundo momento quando possibilitou competência aos estados para institucionalizar suas unidades regionais. A nova Constituição propiciou categorias de organização regional como "aglomerações urbanas" e "microrregiões", abrindo possibilidades para os estados desenvolverem seus planejamentos regionais. Desencadeou-se um novo ciclo de criação de unidades regionais de distintas dimensões, inserções físicas e portes populacionais, "vulgarizando" assim o conceito metropolitano. De um modo geral, leis estaduais diversas criaram unidades e parâmetros para sua organização e gestão gerando situações como "áreas de expansão metropolitana" na legislação de Santa Catarina, e "colar metropolitano" em Minas Gerais. A Constituição previu a criação da categoria 
de Regiões Integradas de Desenvolvimento (RIDEs), instituindo: i) RIDE-DF4; ii) RIDE do Pólo Petrolina e Juazeiro ${ }^{5}$; e iii) RIDE da Grande Teresina ${ }^{6}$.

Em 2003, o território brasileiro continha 26 unidades metropolitanas, sendo que a RIDE-DF, era a única dentre as três instituídas - as outras duas são a RIDE Teresina-Timon e a RIDE Juazeiro-Petrolina - que se inseriam nesse conjunto devido ao porte metropolitano da cidade principal (Cunha \& Pedreira, 2008). Essas unidades metropolitanas concentram-se nas seguintes regiões: a) na Região Sudeste: São Paulo (SP) e MG respectivamente com três e duas unidades; RJ e ES com uma unidade cada; b) na Região Sul: SC possui seis unidades; PR três, e RS uma RM; c) na Região Nordeste: CE, PE e BA já possuíam uma unidade metropolitana dos anos 70, e por leis estaduais o AL, MA, PB e RN constituíram suas unidades totalizando sete nessa Região; d) na Região Norte: Belém constituía a única unidade, sendo criada a unidade de Manaus por lei estadual em 2007 reunindo oito municípios; e) na região Centro-Oeste foi criada a RM de Goiânia, assim como a Aglomeração Urbana de Cuiabá e Várzea Grande, que foi criada recentemente.

A RIDE-DF é constituída pelo DF e municípios do estado de Goiás: Abadiânia, Água Fria, Águas Lindas, Alexânia, Cabeceiras, Cidade Ocidental, Cocalzinho, Corumbá, Cristalina, Formosa, Luziânia, Mimoso, Novo Gama, Padre Bernardo, Pirenópolis, Planaltina, Santo Antônio do Descoberto, Valparaíso de Goiás e Vila Boa; e ainda os municípios do estado de Minas Gerais: Unaí, Buritis e Cabeceira Grande.

Mesmo criadas oficialmente, raras são as experiências de Regiões Metropolitanas no universo descrito que tem efetividade na integração da gestão e planejamento metropolitano. Destacam-se as RMs de Belo Horizonte e de Recife com ênfase no esforço de planejamento e gestão metropolitana e, mais recente, a RM de Belém, por sua legislação metropolitana. Em outros casos, o funcionamento de Consórcios de Serviços Públicos entre municípios tem sido eficaz na gestão integrada, destacando-se a experiência do consórcio denominado "ABCD" que compreende Santo André, São Bernardo, São Caetano e Diadema no estado de São Paulo nos anos 90.

Há uma lacuna quanto às relações metropolitanas no Brasil, como o gap de uma ação integrada de entes federativos no espaço urbano-metropolitano que carece de marco legal e Política Metropolitana ${ }^{7}$ no âmbito de uma nova Política Nacional de Desenvolvimento Urbano, inexistente no Brasil desde 1970.

De outro lado, em diálogo complementar à temática urbano-metropolitana contemporânea, há reiteradas manifestações de ineficácias, limitações e contradições do planejamento urbano, especialmente do instrumento Plano Diretor, sob o panorama da dinâmica real do crescimento urbano. Com essa temática, diversas pesquisas, análises e conhecimento crítico têm se acumulado ao longo dos últimos anos, em trabalhos como: "Da tragédia urbana à farsa do urbanismo reformista: a fetichização dos planos diretores participativos" (Burnett, 2011); "As ilusões do Plano Diretor" (Villaça, 2005); e "Quem disse que ia ser fácil? 10 anos do Estatuto da Cidade" (Schvarsberg, 2012). Tais trabalhos exploraram a qualidade e eficácia da safra de planos diretores produzidos no Brasil. Particularmente, no período posterior à aprovação e sanção da Lei 10.257/2001 - o Estatuto da Cidade - houve o intuito de exemplificar e problematizar tanto a incidência quanto a validação do repertório de planejamento territorial urbano que foi produzido neste período face ao aprofundamento de processos urbanos geradores de consequências, tais como: segregação socioespacial, dispersão do tecido urbano acarretando insustentabilidade ambiental e encarecimento das redes de infraestrutura, serviços e equipamentos urbanos, fenômenos de "gentrificação", dentre outros aspectos que tornam complexo o modelo territorial urbano brasileiro.

\footnotetext{
${ }^{4}$ Envolvendo municípios de Goiás, Distrito Federal e Minas Gerais.

${ }^{5}$ Envolvendo os municípios de Petrolina/PE e Juazeiro/BA.

${ }^{6}$ Envolvendo os municípios: Teresina/PI, Altos/PI, Beneditinos/PI, Coivaras/PI, Curralinhos/PI, Demerval Lobão/PI, José de Freitas/PI, Lagoa Alegre/PI, Miguel Leão/PI, Monsenhor Gil/PI, Timon/MA e União/PI.

${ }^{7} \mathrm{O}$ avanço mais recente nesse sentido deu-se com a Lei do Estatuto da Metrópole, cuja elaboração foi coordenada pelo Deputado Federal Zezéu Ribeiro (PT/BA), sancionada em 2015.
} 


\section{Preparo das informações}

A metodologia aplicada na pesquisa envolveu inicialmente a análise dos planos diretores dos municípios para uma compreensão das lógicas preconizadas de ordenamento territorial, a fim de cotejálas com a dinâmica real das construções aprovadas. No entanto, para ilustrar a preparação e análise das informações foi apresentado abaixo os mapas com a plotagem dos alvarás de construção emitidos no ano de 2015, por cada cidade pesquisada. As bolas amarelas pequenas referem-se aos usos residenciais unifamiliares, e as grandes aos grupos multifamiliares; as bolas vermelhas pequenas relacionaram-se aos usos comerciais de menor porte até $200 \mathrm{~m}^{2}$ e as bolas vermelhas grandes associaram-se a maiores medidas que essa metragem; as bolas azuis pequenas referiram-se aos usos institucionais de menor porte até $200 \mathrm{~m}^{2}$ e as maiores de maior porte; as bolas laranjas ou lilases pequenas referiram-se aos usos mistos de menor porte até $200 \mathrm{~m}^{2}$, e as bolas maiores de maior porte; por fim, as bolas pretas pequenas até 200 $\mathrm{m}^{2}$ referiram-se aos usos industriais de menor porte e as maiores de maior porte. Foram apresentadas na sequência abaixo os mapas com alvarás de construção expedidos em 2015, com a representação em bolas coloridas conforme definido acima nas cidades de Taguatinga e Samambaia do Distrito Federal, e de Águas Lindas e Planaltina de Goiás. Ver Figura 2.

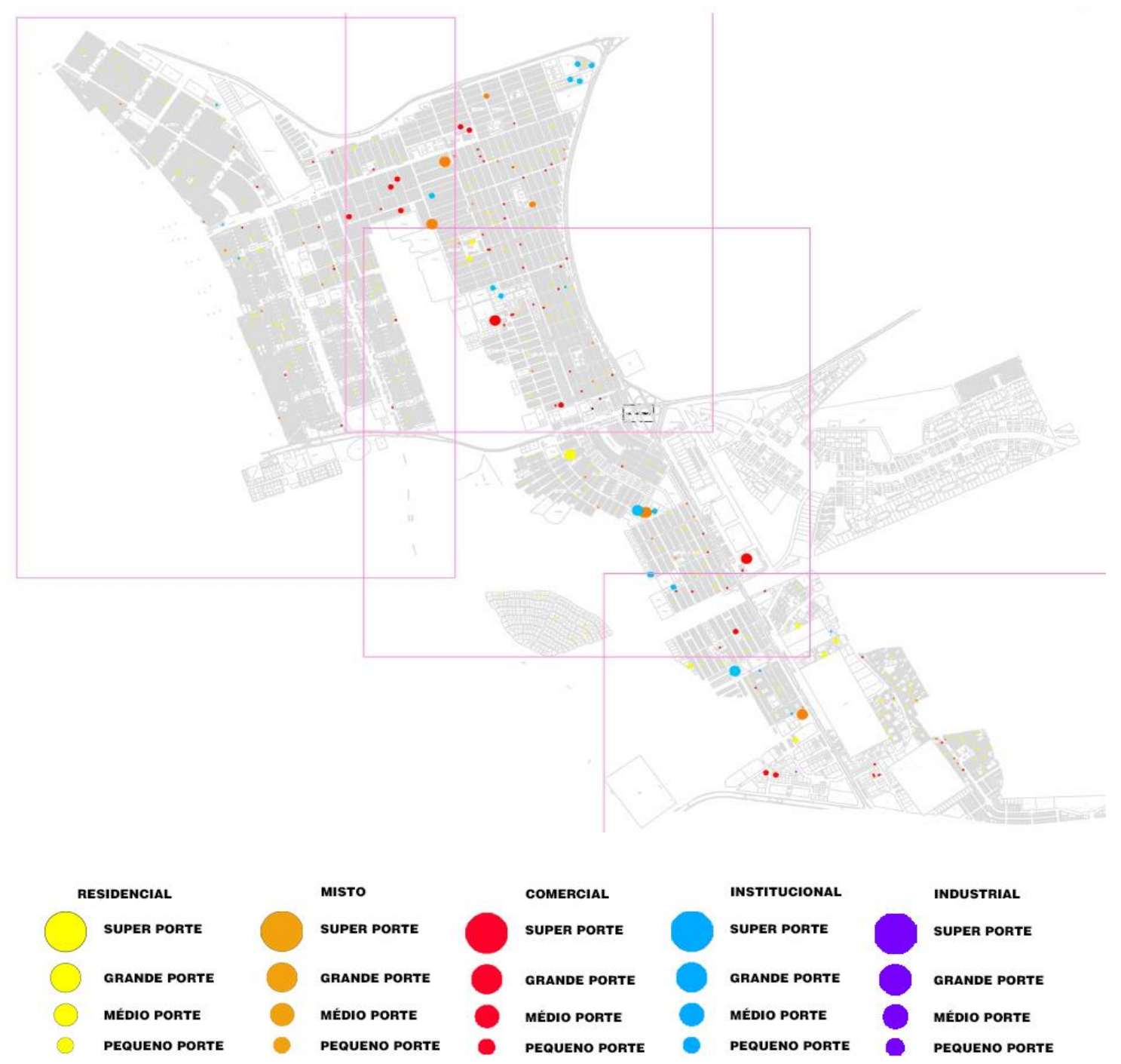

Figura 2 - Taguatinga/DF - Alvarás de Construção emitidos em 2015. Fonte: Autor, 2018. 


\section{Análise dos resultados da pesquisa}

Com respeito às dinâmicas urbana e imobiliária, relativas aos projetos de edificações residenciais uni e multifamiliares, comerciais, mistas, institucionais e industriais aprovados no período de 2012 a2015, os dados apurados na pesquisa revelaram nuances peculiares nos resultados, considerando-se as quatro cidades onde foi aplicada a metodologia: Águas Lindas e Planaltina em Goiás, Samambaia e Taguatinga no DF.

A avaliação da primeira hipótese, de que os padrões de planejamento e planos diretores têm baixo controle/incidência nas formas do crescimento urbano na dinâmica metropolitana da AMB, foi de que esse enunciado embora não pudesse ser negado, mereceria problematização com a concepção da dinâmica metropolitana dos anos em tela. Nos casos do DF, os Planos Diretores de Samambaia e Taguatinga encontraram-se defasados com baixa média de incidência no controle do uso do solo. Entretanto, nos casos de Águas Lindas e Planaltina de Goiás, os Planos Diretores, embora vigentes, foram desconhecidos na gestão urbana. Na avaliação da segunda hipótese, os dados empíricos levantados apontaram no quadro da dinâmica metropolitana da AMB, o predomínio de projetos aprovados de atividades econômicas e institucionais (comércio e serviços, mistos, industriais e instituições) e de residência multifamiliar vertical, com tendência efetiva em expressar maior dinâmica e autonomia urbana das cidades e núcleos urbanos. E na terceira hipótese, no oposto, houve o predomínio de projetos aprovados de residências unifamiliares e multifamiliares horizontais a expressar baixo dinamismo e autonomia urbana, reforçando assim o caráter de cidades dormitórios dependentes de uma cidade-mãe, no caso de Brasília. Foi necessário estabelecer uma distinção referente à dinâmica e autonomia urbana considerando aqueles predomínios citados nas duas cidades do DF e nas duas cidades de Goiás.

\section{Resultados da pesquisa nas cidades de Águas Lindas e Planaltina (Estado de Goiás), e das cidades-satélites de Samambaia e Taguatinga (Distrito Federal).}

Quanto aos instrumentos urbanísticos de ordenamento territorial, controle do uso e ocupação do solo, especialmente sobre o Plano Diretor, e considerando também os padrões desiguais, pôde-se estabelecer uma diferenciação entre a baixa média de incidência nos casos das cidades do DF e nos casos das cidades de Goiás, que integram a periferia metropolitana, com a diminuta incidência, que se define como "desconhecimento da presença do Plano Diretor e da efetividade de seus instrumentos na gestão urbana praticada".

Em Planaltina, devido à série histórica de alvarás, sugeriram-se algumas tendências quanto aos projetos aprovadas no sentido de promover maior autonomia a cidade, com incremento de atividades, tais como: comerciais, institucionais, usos mistos e residenciais multifamiliares, como sugere a Figura 3. Houve ligeira tendência de verticalização, especialmente no Setor Norte. Todavia, o predomínio absoluto dos usos residenciais unifamiliares denotou forte caráter de cidade-dormitório, onde boa parte dos moradores é dependente da busca de oportunidades de trabalho, emprego, serviços de educação e saúde fora da cidade, principalmente na direção de Brasília. Assim, permanece o fluxo pendular diário de parte significativa da população no eixo Brasília - Planaltina/Goiás. Pôde-se perceber na leitura do Plano Diretor de Planaltina, diretrizes de zoneamento no sentido de usos comerciais nas seis principais vias coletoras da cidade. Entretanto, os levantamentos realizados demonstraram a aprovação de construções residenciais, na maioria dos casos unifamiliares nessas áreas, contrariando claramente o planejamento urbano preconizado no seu Plano Diretor. Ao contrário, foram detectados usos comerciais e mistos em áreas destinadas exclusivamente à zona residencial. As construções que foram aprovadas em falta de sintonia com o Plano Diretor denotaram claramente sua ineficácia, e necessidade de atualização do planejamento da cidade, mais direcionada à dinâmica urbana em andamento, de forma a estimular maior autonomia de Planaltina/GO. Cabe destacar o papel importante de dois grandes equipamentos urbanos: o Shopping Center no Setor Leste e a Rodoviária Interestadual no Setor Norte, implantados em anos recentes. Percebeu-se o potencial de impacto desses equipamentos na dinamização, não só dos bairros onde foram inseridos, mas em todo o conjunto da cidade. 


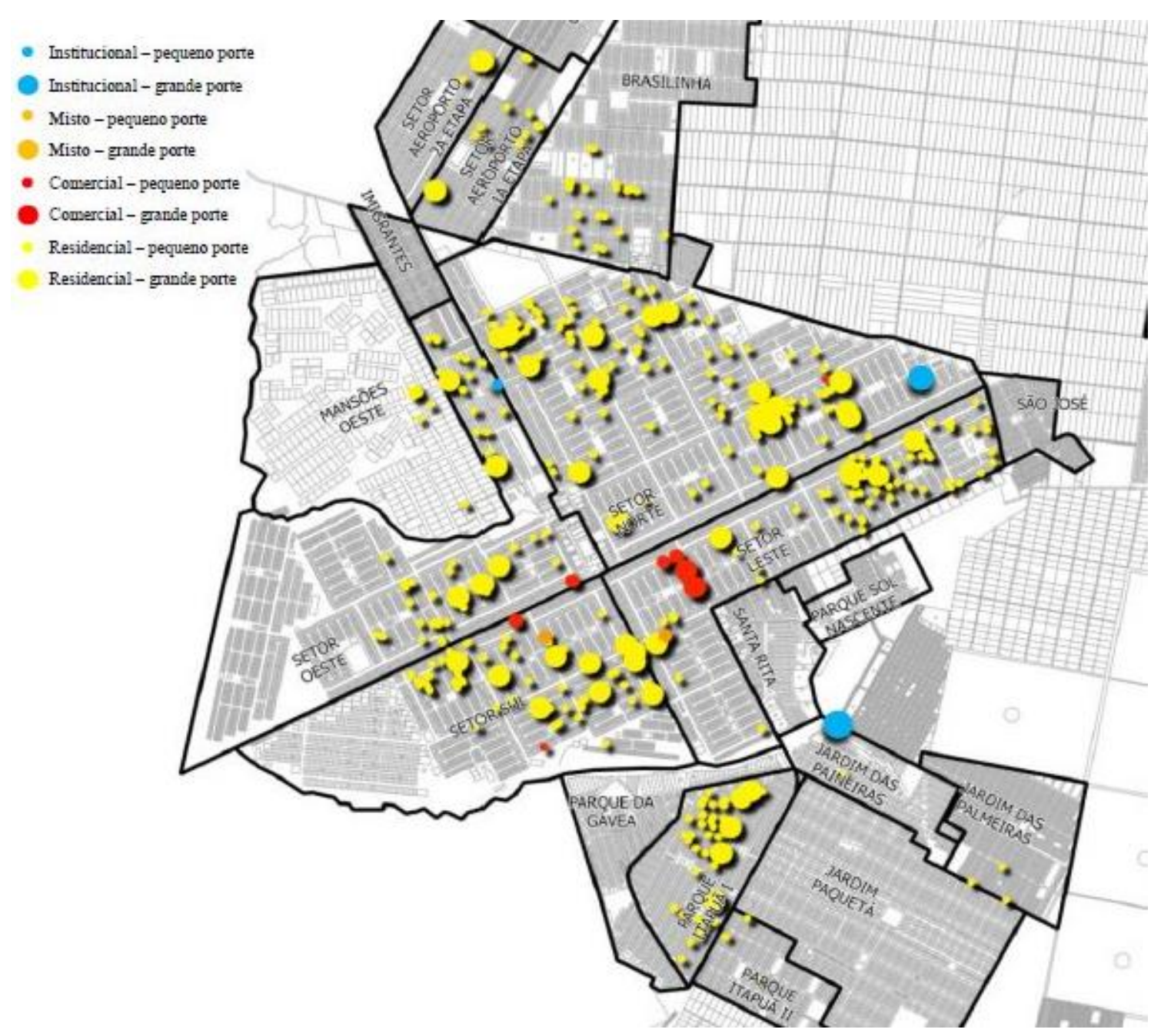

Figura 3 - Planaltina de Goiás - Alvarás de Construção emitidos em 2015. Fonte: Autor, 2018.

Em Águas Lindas, destacou-se uma série histórica de alvarás no ano de 2015, pois houve queda no total de $12,1 \%$ em todos os alvarás para as novas construções, sendo que 99,3\% permaneceram como residenciais, repetindo o mesmo padrão de predomínio residencial dos quatro anos anteriores. Contudo, as residências unifamiliares diminuíram mais quando comparadas à proporção das multifamiliares em relação aos anos anteriores; essas residências passaram de 1,5\% para 5,1\% de novos alvarás residenciais, com a construção de 91 novos edifícios verticais, continuando a tendência de crescimento das residências multifamiliares sobre unifamiliares; tendência apontando a amenização do caráter de cidade-dormitório conforme a hipótese da pesquisa. Notou-se que na parte norte da rodovia BR-070, que divide a cidade, houve continuidade do crescimento de novas construções, porém com expansão na direção oeste e leste, como sugere a Figura 4. Na parte sul, abaixo da rodovia, o crescimento continuou e se ampliou significativamente, com novas concentrações de construções residenciais multifamiliares em edifícios verticais. Das construções com destinação comercial, notou-se continuidade de concentração em três regiões, com somente três novas construções comerciais na região ao sul da rodovia. Também na parte sul da rodovia, houve crescimento residencial multifamiliar, entretanto o mesmo não foi acompanhado de novas construções comerciais. Em 2016, houve queda de 49,2\% no total de novas construções, permanecendo o total de alvarás residenciais em $99,2 \%$, mantendo o padrão de predomínio residencial de novas construções, em que unifamiliares diminuíram para 84,8\%, enquanto multifamiliares passaram para 15,2\%, um crescimento notável em relação aos anos anteriores. Mesmo com a queda bruta total das novas construções, aprofundou a tendência no sentido de maior autonomia. Em 2017, existiu uma estabilização, com crescimento mínimo na residência unifamiliar e acentuado decréscimo na residência 
multifamiliar. Destacou-se o crescimento nas construções comerciais alcançando 2\%, o maior da série dos anos pesquisados. Cruzando os alvarás de construção, os alvarás de novas construções com os dados de arrecadação do Imposto de Circulação de Mercadorias e Serviços (ICMS ${ }^{8}$ ), pôde-se afirmar que existiu correlação entre a dinâmica de crescimento construtivo da cidade com a dinâmica geral de crescimento de atividades econômicas, especialmente comércios e serviços.

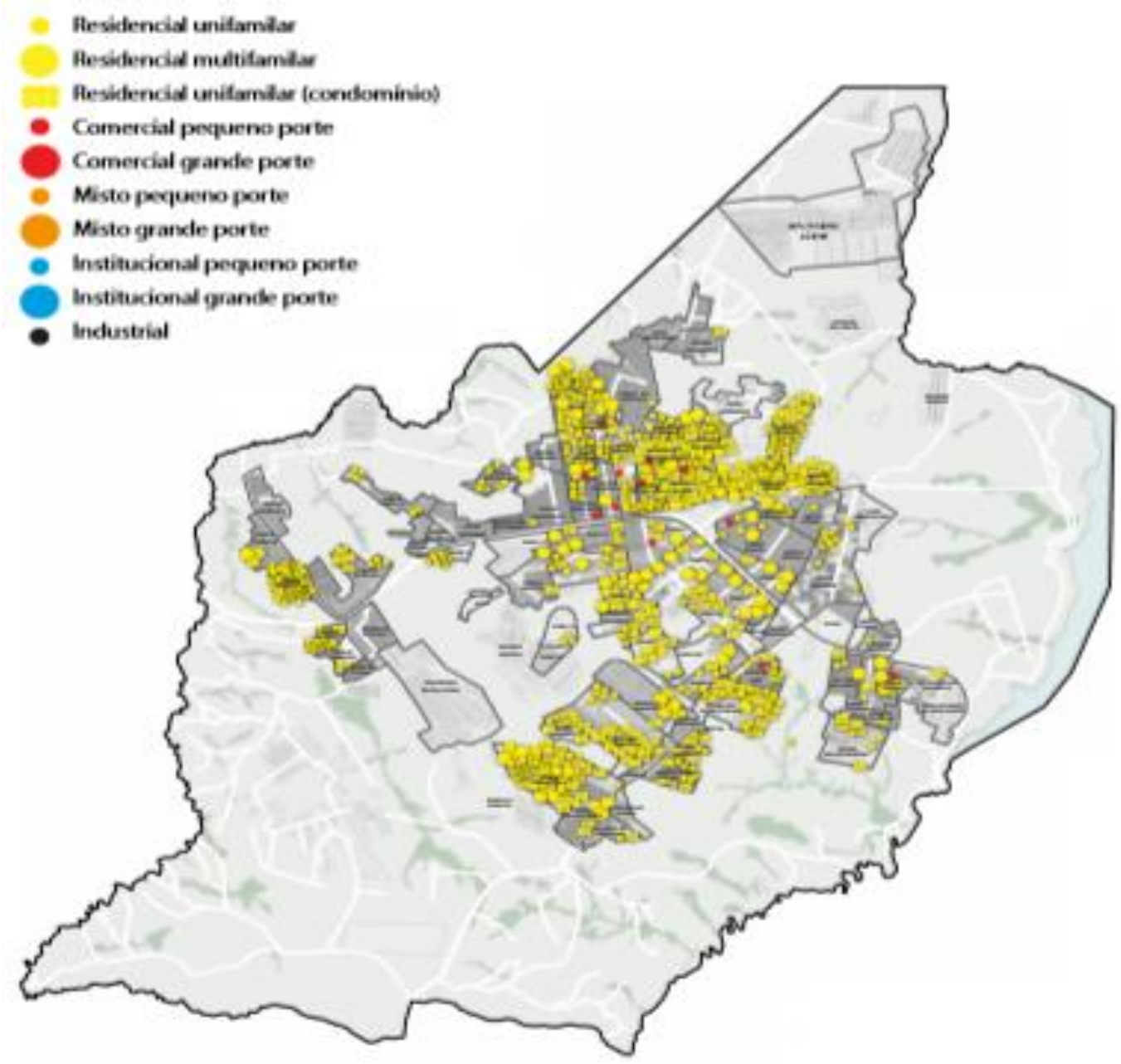

Figura 4 - Águas Lindas de Goiás - Alvarás de Construção emitidos em 2015. Fonte: Autor, 2018.

Entretanto, o Plano Diretor e seu zoneamento não foi capaz de induzir uma dinâmica de crescimento econômico como proposto. A área proposta para constituir um Centro Urbano de menor restrição, como centralidade de dinamização econômica e social, não se constituiu com novas construções comerciais e de uso misto, tendo somente poucas novas construções residenciais multifamiliares. Quanto às áreas propostas para constituírem uma Área de Desenvolvimento Econômico, tampouco se constituíram como tal; tendo em vista que a única ocupação com novas construções foi com relação às residências unifamiliares, sem a característica de dinâmica econômica proposta no zoneamento do Plano Diretor. Concluiu-se que o Plano Diretor teve baixa eficácia em orientar e estimular um crescimento e ordenamento da cidade na perspectiva de maior autonomia, em contraponto à consolidação de seu caráter de cidade-dormitório.

Em Samambaia/DF, na série histórica, observou-se que os três primeiros anos mantiveram média geral de 300 alvarás/ano, e houve queda significativa na quantidade de construções no ano de 2015, mantendo-se o percentual de alvarás emitidos de uso residencial e comercial. Detectou-se tendência geral

\footnotetext{
${ }^{8}$ ICMS - Imposto sobre circulação de mercadorias e serviços.
} 
de queda no crescimento do uso residencial multifamiliar. 0 boom residencial multifamiliar de 2012 foi resultado do programa habitacional Minha Casa Minha Vida, e os alvarás aprovados não foram necessariamente de obras daquele ano; empreendimentos dessa natureza demoram muito tempo até terem seus alvarás expedidos, sendo somente liberados de acordo com a demanda junto aos órgãos públicos. Alvarás de construções unifamiliares de pequeno porte foram, na maioria das vezes, regularizações de construções existentes, não referentes a novas construções, pois em Samambaia foi inicialmente construída fora das diretrizes do seu Plano Urbano. O Plano Diretor de Samambaia determinou as diretrizes de integração com Taguatinga e Ceilândia, ressaltando o objetivo de viabilizar as condições urbanísticas necessárias às autonomias socioeconômicas da cidade por meio de comércio, serviços e indústria. Quanto à integração entre as três cidades, ainda não ocorreu conurbação entre as mesmas devido às barreiras ambientais. Houve diminuição de viagens entre Samambaia e o Centro (Plano Piloto) demonstrando aumento da autonomia da cidade e formação de novo polo de centralidade regional Taguatinga/Águas Claras, concorrendo com a centralidade do Plano Piloto. Esses cenários ratificam parcial concretização dos objetivos do Plano Diretor: dinamização da área e maior autonomia com relação ao Centro.

0 metrô foi um importante fator que acompanhou o crescimento da cidade e influenciou sua forma; atualmente, a linha do metrô vai da zona leste ao Centro Urbano, porém há previsão de expansão dessa linha para além desse limite. Os três anos iniciais do estudo (2012 a 2014), revelaram tendência crescente de usos comerciais, institucionais e equilíbrio de uso misto, apontando maior autonomia da cidade. As construções, com exceção das residências unifamiliares, dependem de financiamentos bancários suscetíveis às dinâmicas da economia, o que foi revelado no contraste da quantidade de alvarás registrada em 2012 e 2015.

A área central coincide com o alcance do metrô, indicando a relevância da relação entre transportes coletivos de massa e a consolidação do tecido urbano, além da dinamização das áreas próximas às estações, onde se vê comércios de maior porte.

A análise dos alvarás e crescimento de Samambaia nos últimos anos demonstrou que as diretrizes do Plano Diretor foram seguidas como estímulo ao adensamento e à valorização imobiliária, especialmente nas áreas vizinhas ao metrô, com o reforço das ligações viárias com as demais cidades e dinamização de uso do solo, conforme Figura 5. Entretanto, fatores fundamentais como melhoria de espaços públicos voltados para o pedestre e a criação de canaleta exclusiva de transporte de massa e coletivo ao longo do anel viário não foram atendidos, comprometendo a efetividade do Plano Diretor. 


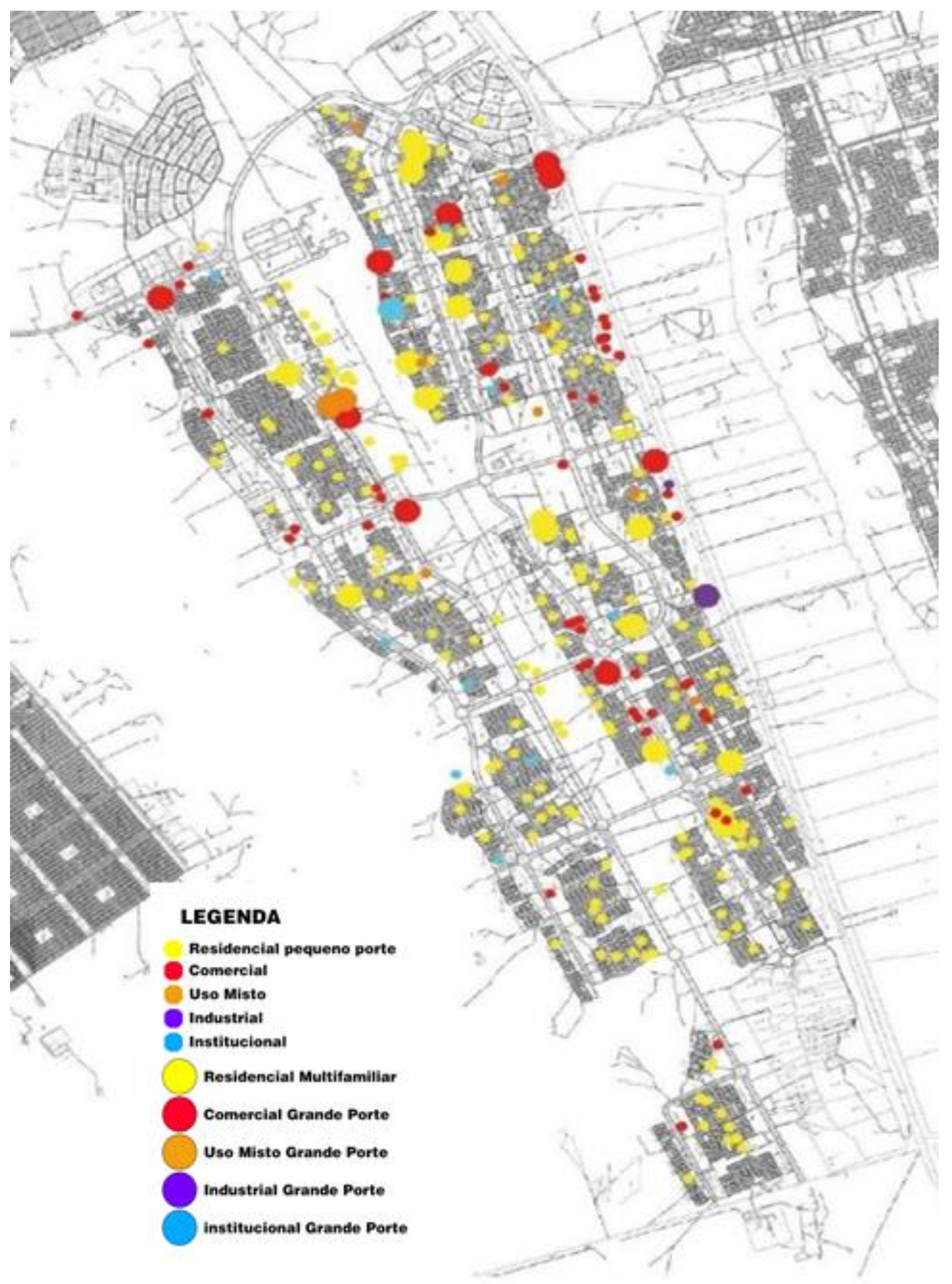

Figura 5 - Samambaia/DF - Alvarás de Construção emitidos em 2015. Fonte: Autor, 2018.

Em Taguatinga/DF, a análise dos alvarás e do crescimento de Taguatinga nos últimos anos face às diretrizes do Plano Diretor expressas na atribuição de Coeficientes de Aproveitamento para as distintas áreas da cidade, revelou aspectos relevantes. Nos parâmetros urbanísticos definidos no Plano Diretor estão definidos como "lotes de menor restrição" os que permitem mais atividades, porém impedem atividades consideradas de alto grau de incomodidade como atividade industrial nas áreas com lotes vizinhos à Avenida Central. Pôde ser considerado como o "Centro de Taguatinga", o cruzamento do eixo que divide Taguatinga Norte e Sul, traçando-se um raio tendo como centro a praça central de Taguatinga, 
ou seja, cerca de 3km. Essa área possui alto Coeficiente de Aproveitamento (CA), com valor 7 (sete). Destacou-se a área delimitada pelas Quadras Industriais Norte que possui Coeficiente de Aproveitamento 4 (quatro). A área delimitada pelo Centro Metropolitano, no qual estão edificados grandes equipamentos, como o novo Centro Administrativo, estádio e rodoviária possuem Coeficientes de Aproveitamento de 4 (quatro) e 5 (cinco). A área das Quadras Sul possui Coeficiente de Aproveitamento 4 (quatro); e finalmente a grande Avenida Comercial Norte e Sul, na área central, possui o maior e Coeficiente de Aproveitamento, com valor 7 (sete).

O Plano Diretor definiu a Avenida Hélio Prates, com lotes propostos como "média restrição", a área que corta a cidade transversalmente ligando as cidades de Taguatinga com Ceilândia, maior população do DF com 400 mil habitantes, e seu Coeficiente de Aproveitamento é 9 (nove), o mais elevado da cidade. As áreas ao longo do Pistão Sul, importante via que circunda a cidade, possuem também Coeficiente de Aproveitamento 9 (nove), onde foram implantados grandes empreendimentos comerciais como shopping center, supermercados e a Universidade Católica. Destacaram-se áreas de maiores quantidades de Alvarás de Construção em 2015, tais como o empreendimento "Península", com várias torres altas de apartamentos, que possui um Coeficiente de Aproveitamento 5 (cinco); entretanto, como é um lote de grandes dimensões, nele se implantou o maior adensamento da cidade com mais de 1000 (mil) novas unidades residenciais e acréscimo de população de cerca de 4 mil moradores. Nesse sentido, confirmouse a hipótese de que as áreas propostas para maior adensamento (coeficientes 7 e 9) não corresponderam efetivamente à dinâmica imobiliária real ocorrida na cidade, conforme a Figura 2. Na relevante Avenida Hélio Prates, observando-se os alvarás expedidos, não foram implantados empreendimentos no porte previsto nos Coeficientes de Aproveitamentos, de valor 9 para esta área, conforme propostos no Plano Diretor. Apontou-se também a confirmação da hipótese de que as áreas propostas para maior adensamento não corresponderam à dinâmica imobiliária real ocorrida na cidade.

\section{Conclusão}

O segundo plano da dinâmica imobiliária, analisada tanto em suas incongruências com o planejamento quanto com a gestão urbana, assim como as limitações da implementação dos planos diretores, dialogou com o processo de metropolização marcado por enormes desigualdades e simultâneas complementaridades econômico-funcionais e territoriais; reproduziu e reforçou a tendência centralizadora no "coração" da área metropolitana. Essas complementaridades funcionais, econômicas e territoriais resultaram, complexamente, em conformar interdependências entre essas diversas cidades e núcleos urbanos em razão de seus fluxos (pessoas e mercadorias) e fixos (equipamentos, empregos, atividades, infraestrutura e serviços).

Os padrões de planejamento, planos diretores, projetos e normas foram bastante desiguais entre as cidades ou núcleos urbanos do DF e as cidades da AMB. Não obstante a desigualdade, esses padrões tiveram em comum a dificuldade de incidir mais fortemente nas formas de crescimento urbano na dinâmica metropolitana.

As complementaridades funcionais no sentido dos fluxos e dos fixos que se estabeleceram em toda AMB nesta dinâmica de metropolização constituem um ATIVO no sentido de redesenhar, na perspectiva da complementaridade, os padrões de planejamento, planos diretores e normas urbanísticas. As interdependências puderam ser vistas como potencialmente geradoras de mecanismos de intercambialidade para os solos, potenciais construtivos e regulamentação urbanística, bem como a aplicação dos instrumentos de política urbana ${ }^{9}$ do Estatuto da Cidade, na perspectiva proposta no Estatuto da Metrópole.

Em uma abordagem que combina complementaridade, interdependência e intercambialidade, foi possível coordenar seus planos diretores, como instrumentos matrizes do manejo social de solos, potenciais construtivos e instrumentos de política urbana em um planejamento e gestão metropolitana

\footnotetext{
${ }^{9}$ Tais como a transferência de direito de construir, potenciais construtivos e outorgas onerosas do direito de construir.
} 
integrada. Contribuíram para essa coordenação os levantamentos e análises aqui realizados, com base para a ampliação do quadro empírico a ser complementado e com a investigação nas demais cidades e núcleos urbanos constituintes da AMB. A metodologia desenvolvida na primeira fase da pesquisa proporcionou a reiteração das hipóteses construídas com três formulações que sugeriram novos testes para a continuidade da pesquisa aplicada às cidades da AMB: A) na dinâmica metropolitana da $A M B$, o predomínio de projetos aprovados em atividades econômicas e institucionais indicou uma tendência a expressar maior dinâmica e autonomia urbana; B) no oposto, o predomínio de projetos aprovados de residências unifamiliares expressou baixo dinamismo e autonomia urbana; reforçou deste modo o caráter de cidades-dormitórios dependentes de uma cidade-mãe; C) os padrões de planejamento, planos diretores, projetos e normas urbanísticas tiveram baixo controle/incidência no crescimento urbano e na dinâmica metropolitana da AMB.

A investigação detectou a limitação e desarticulação daquelas bases urbanísticas e institucionais, sobretudo dos instrumentos urbanísticos vigentes para orientar e controlar a dinâmica do crescimento urbano. Não obstante a desorganização e limitações técnicas institucionais das administrações públicas, o alvará de construção demonstrou ser um indicador de pesquisa confiável, propiciando um referencial de leitura consistente dos usos e ocupações dos solos implementados. Conclui-se que a limitada aplicação dos Planos Diretores, suas diretrizes, zoneamentos e parâmetros urbanísticos, na orientação do crescimento urbano ocorrido ratificou a demanda por um sistema de planejamento e gestão urbana e territorial integrada para a AMB.

\section{Referências}

Burnett, F. L. (2011). Da tragédia urbana à farsa do urbanismo reformista: fetichização dos planos diretores participativos. São Paulo: Annablume.

Cunha, E. M. P., \& Pedreira, R. S. (2008). Série: Como andam as Regiões Metropolitanas (Vol. 1, Hierarquização e Identificação de Espaços Urbanos). Brasília: Ministério das Cidades.

Ferreira, I. C. B. (1985). 0 processo de urbanização e a produção do espaço metropolitano de Brasília. In A. Paviani (Org.), Brasília, Ideologia e Realidade: o espaço urbano em questão (1. ed., pp. 43-56). São Paulo: Ed. Projeto.

Ferreira, I. C. B., \& Steimberguer, M. (2005). 0 modelo de gestão de Brasília e as Políticas Urbanas Nacionais. Cadernos Metrópole, 7(14), 67-83.

Gottdiener, M. (1993). A produção social do espaço urbano. São Paulo: Editora da Universidade de São Paulo, São Paulo.

Schvarsberg, B. (2012). Quem disse que ia ser fácil? 10 anos do Estatuto da Cidade. In A.C.T. Ribeiro, L.F. Vaz, \& M.L.P. Silva (Org.), Leituras da Cidade (1. ed., pp. 105-117). Rio de Janeiro: ANPUR, LetraCapital.

Villaça, F. (2005). As ilusões do plano diretor. São Paulo: Edição do autor.

Editor: Rodrigo José Firmino

Recebido: Maio 06, 2018

Aprovado: Set. 13, 2018 